\title{
Substituted nitrogen-bridged diazocines
}

\author{
Pascal Lentes, Jeremy Rudtke, Thomas Griebenow and Rainer Herges ${ }^{*}$
}

\author{
Full Research Paper \\ Address: \\ Otto Diels-Institute of Organic Chemistry, Christian Albrechts \\ University Kiel, Otto-Hahn-Platz 4, 24118 Kiel, Germany \\ Email: \\ Rainer Herges* - rherges@oc.uni-kiel.de \\ * Corresponding author \\ Keywords: \\ bridged azobenzene; diazocine; photopharmacology; photoswitch; \\ triazocine; visible light switch; water-soluble switch
}

\author{
Beilstein J. Org. Chem. 2021, 17, 1503-1508. \\ https://doi.org/10.3762/bjoc. 17.107 \\ Received: 05 March 2021 \\ Accepted: 11 June 2021 \\ Published: 25 June 2021 \\ Associate Editor: C. Stephenson \\ (c) 2021 Lentes et al.; licensee Beilstein-Institut. \\ License and terms: see end of document.
}

\begin{abstract}
Novel nitrogen-bridged diazocines (triazocines) were synthesized that carry a formyl or an acetyl group at the $\mathrm{CH}_{2} \mathrm{NR}_{\text {-bridge and }}$ bromo- or iodo-substituents at the distant phenyl ring. The photophysical properties were investigated in acetonitrile and water. As compared to previous approaches the yields of the intramolecular azo cyclizations were increased (from $\approx 40$ to $60 \%$ ) using an oxidative approach starting from the corresponding aniline precursors. The $Z \rightarrow E$ photoconversion yields in acetonitrile are 80-85\% and the thermal half-lives of the metastable $E$ configurations are 31-74 min. Particularly, the high photoconversion yields ( $\approx 70 \%$ ) of the water-soluble diazocines are noteworthy, which makes them promising candidates for applications in photopharmacology. The halogen substituents allow further functionalization via cross-coupling reactions.
\end{abstract}

\section{Introduction}

Diazocines (bridged azobenzenes) are frequently used photoswitches with outstanding photophysical properties. Parent diazocine $\left(\mathrm{CH}_{2}-\mathrm{CH}_{2}\right.$-bridged) exhibits well-separated $n-\pi^{*}$ transitions, which allow excellent photoconversion between the $Z$ and $E$ configurations $\left((Z \rightarrow E)_{385 \mathrm{~nm}}=92 \%,(E \rightarrow Z)_{525 \mathrm{~nm}}>\right.$ $99 \%$ in $n$-hexane) with light in the visible region [1]. Moreover, the $Z$-boat configuration is the thermodynamically stable isomer [2-9]. The latter property (i.e., the inverted stability compared to azobenzenes) makes them promising candidates for applications in photopharmacology. In the majority of azobenzenebased photopharmacophores, the bent $Z$ configuration is biologically inactive [10-12]. Hence, (and in contrast to azobenzenes) the thermodynamically stable and biologically inactive $Z$-isomer can be administered and switched on with light at the site of interest with spatiotemporal resolution. Moreover, the photoconversion yield for the $E \rightarrow Z$ isomerization is quantitative (within the detection limit of UV and NMR spectroscopy). A high efficiency in switching the biological activity off is important to avoid side effects of residual concentrations of the active form [13].

Water solubility and high $Z \rightarrow E$ switching efficiencies in water are additional important criteria for applications in biological environments [14]. Our previously published NAc-bridged diazocine 10c (Scheme 1, Table 1) exhibits both properties [15]. This is in stark contrast to the $\mathrm{CH}_{2}-\mathrm{CH}_{2}$ and $\mathrm{S}-\mathrm{CH}_{2}$-bridged diazocines and the majority of azobenzenes [9,16-20]. Spurred by the promising properties of $\mathrm{CH}_{2}-\mathrm{NR}$-bridged diazocines 
(triazocines), we now explored this class of photoswitches and developed synthetic access to these photochromes (Figure 1).

\section{Results and Discussion}

\section{Synthesis}

The first three stages of the synthesis of $\mathrm{CH}_{2}-\mathrm{NR}$-bridged diazocines are analogous to the previously described synthesis of $\mathrm{CH}_{2}-\mathrm{NH}$-bridged diazocine [15]. The single Boc-protected 1,2-phenylenediamine (2, Scheme 1$)$ is reacted with halogensubstituted 2-nitrobenzyl bromides 3 [21] forming $N$-benzylanilines 4, which were protected with Fmoc chloride to accomplish an orthogonal protective group strategy. The removal of the Boc groups from compounds 5 with TFA gave the mixed aniline and nitro precursors 6.

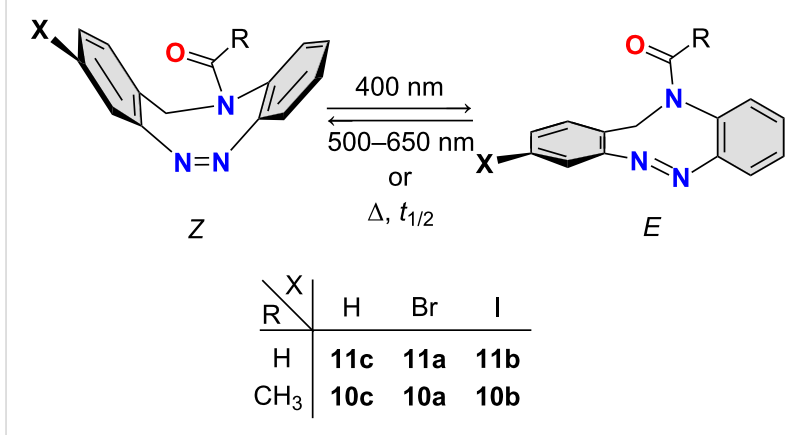

Figure 1: Bridged diazocines synthesized and investigated in this work.

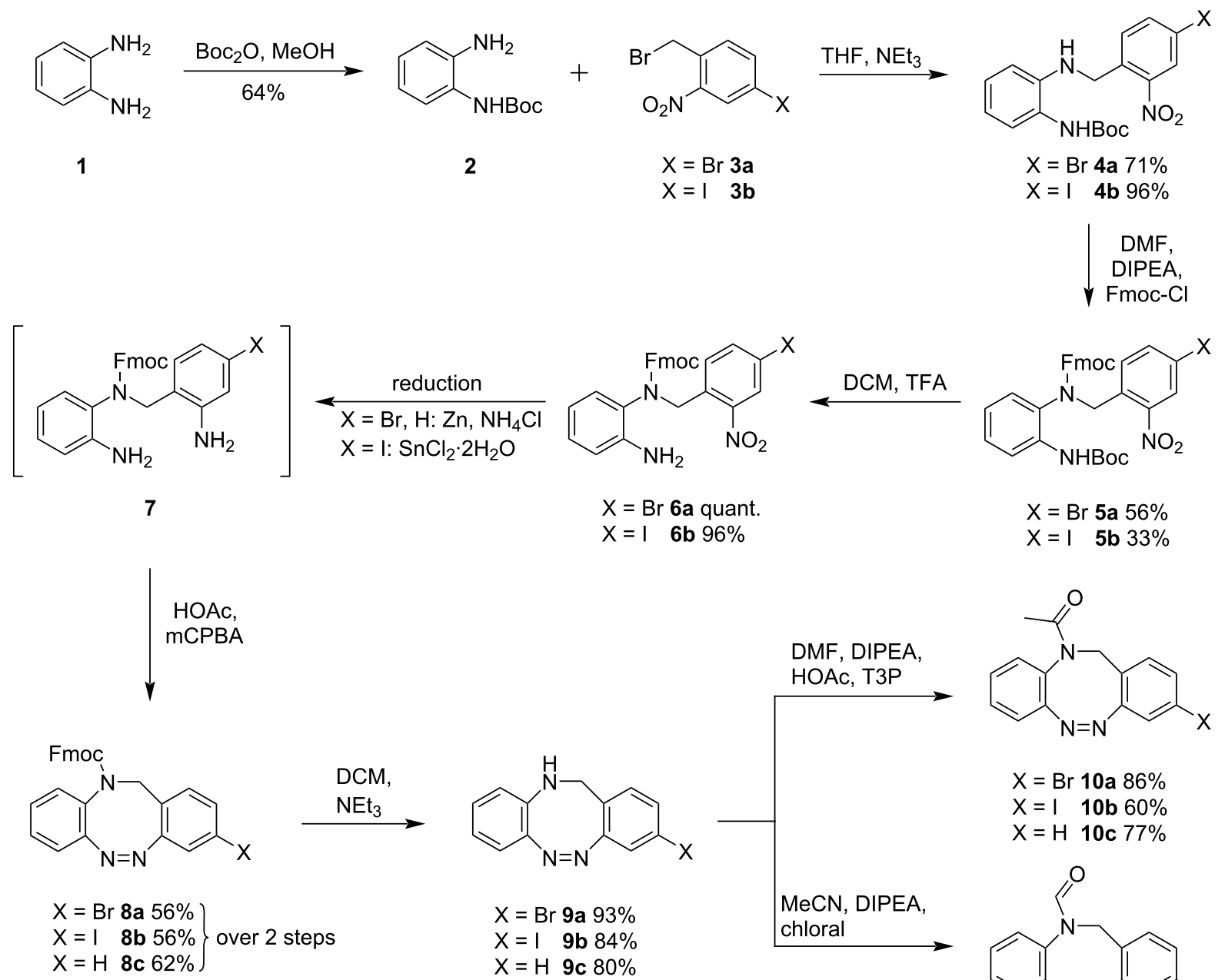

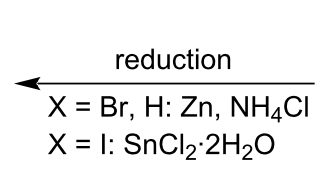


In previous approaches, the nitro groups were reduced to hydroxylamines with zinc and oxidized to the corresponding nitroso compounds with iron(III) to perform an intramolecular Baeyer-Mills reaction [15,21]. We found that a complete reduction of the nitro group to aniline 7 and oxidation with mCPBA is increasing the yield of the intramolecular cyclization from $39 \%$ to $62 \%$ (over two steps) for the unsubstituted diazocine $\mathbf{8 c}$ as compared to the pathway via the hydroxylamine. The 3 -bromo 8a and 3-iodo $\mathbf{8 b}$ compounds were obtained in 56\% yield using the oxidative method of Trauner [22] with mCPBA. The Fmoc groups were removed with $\mathrm{NEt}_{3}$ to yield the
NH-diazocines 9. The acetylated diazocines 10a-c were synthesized using a mixed anhydride of acetic acid and T3P (propanephosphonic acid anhydride). The formylation of NH-diazocines 9a-c was accomplished with chloral [23] under non-acidic conditions.

\section{Investigation of the photophysical properties}

The UV-vis spectra of diazocines 10a-c, and 11a-c were recorded in acetonitrile at $25{ }^{\circ} \mathrm{C}$. All compounds exhibit an $n-\pi^{*}$ transition at about $400 \mathrm{~nm}(Z \rightarrow E$ conversion $)$ and an $n-\pi^{*}$ transition at about $520 \mathrm{~nm}(E \rightarrow Z$ conversion, Figure 2, Table 1).

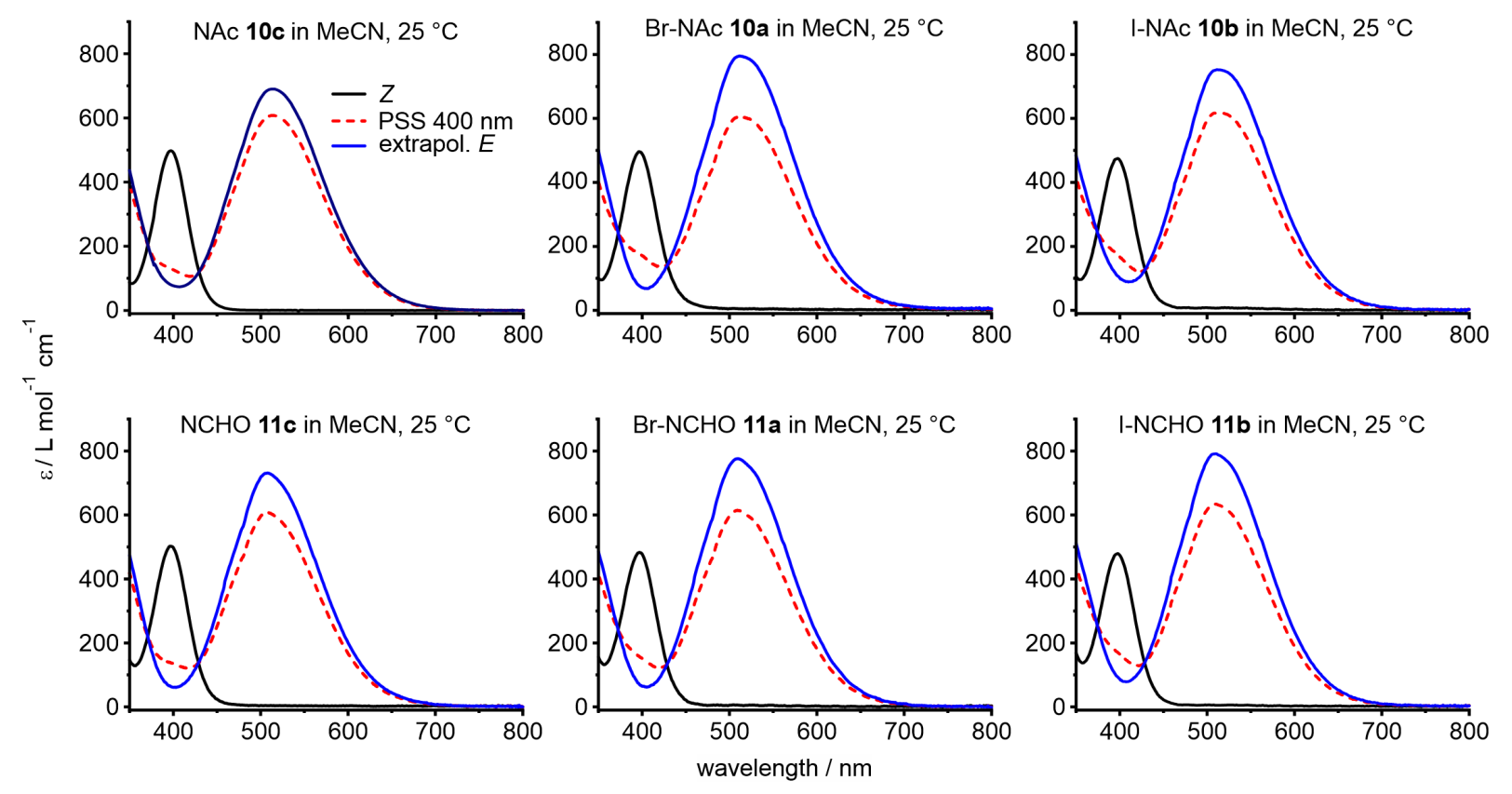

Figure 2: UV-vis spectra of 3-bromo and 3-iodo, and unsubstituted $\mathrm{CH}_{2} \mathrm{NAc}$-bridged (10a-c) and $\mathrm{CH}_{2} \mathrm{NCHO}$-bridged (11a-c) diazocines. The spectra of $Z$-isomers are given in black, the photostationary states at $400 \mathrm{~nm}$ are represented as dashed red lines and the extrapolated spectra of the pure E-isomers are in blue.

Table 1: Photophysical properties of $N$-diazocines $10 a-c$ and $11 a-c$ in acetonitrile

\begin{tabular}{|c|c|c|c|c|c|c|c|c|}
\hline & \multicolumn{8}{|c|}{ acetonitrile } \\
\hline & $\lambda_{\max (\mathrm{Z})}$ & $\lambda_{\max (\mathrm{E})}$ & $\varepsilon_{\lambda \max (Z)}$ & $\varepsilon_{\lambda \max (\mathrm{E})}$ & $\Gamma_{Z \rightarrow E^{a}}$ & $t_{1 / 2}\left(25^{\circ} \mathrm{C}\right)$ & $E_{\mathrm{A}}$ & $\ln (A)$ \\
\hline & \multicolumn{2}{|c|}{$\mathrm{nm}$} & \multicolumn{2}{|c|}{$\mathrm{L} \mathrm{mol}-1 \mathrm{~cm}^{-1}$} & $\%$ & $\min$ & $\mathrm{kJ} \mathrm{mol}^{-1}$ & \\
\hline Br-NAc 10a & 397 & 515 & 495 & 791 & 81 & 30.9 & 93.4 & 29.8 \\
\hline I-NAc 10b & 397 & 517 & 480 & 778 & 82 & 28.6 & 87.0 & 27.3 \\
\hline $\mathrm{NCHO} 11 \mathrm{c}$ & 397 & 509 & 502 & 760 & 85 & 74.0 & 88.4 & 26.9 \\
\hline Br-NCHO 11a & 397 & 509 & 469 & 784 & 82 & 49.9 & 93.9 & 29.5 \\
\hline I-NCHO 11b & 398 & 511 & 483 & 798 & 80 & 48.1 & 90.9 & 28.3 \\
\hline NAc 10c & 397 & 513 & 495 & 759 & 88 & 29.5 & 87.6 & 27.5 \\
\hline
\end{tabular}

aExtrapolated values (for details, see Supporting Information File 1, section IV). 
Irradiation with $400 \mathrm{~nm}$ gives the metastable $E$-isomers of the acetylated and formylated derivatives $\mathbf{1 0}$ and $\mathbf{1 1}$ with good photoconversion yields $(\Gamma)$ of $80-85 \%$ (Table 1$)$ in acetonitrile. A complete $E \rightarrow Z$ conversion ( $>99 \%$ ) can be achieved with light between 520 and $600 \mathrm{~nm}$. The unsubstituted acetylated and formylated diazocines 10c and 11c exhibit similar conversion yields ( $88 \%$ and $85 \%$ ) and halogenation as well does not have a significant influence. However, thermal half-lives $\left(t_{1 / 2}\right)$ of the metastable $E$-isomers of the 3 -bromo and 3-iodo $N$-acetyl diazocines 10a and 10b $(\approx 30 \mathrm{~min})$ are significantly smaller than the half-lives of the corresponding bromo and iodo $N$-formyl derivatives 11a and 11b ( $\approx 50 \mathrm{~min})$. In general, halogenation decreases the half-lives compared to unsubstituted diazocines $10 \mathrm{c}$ and $11 \mathrm{c}$. The activation barrier $\left(E_{\mathrm{A}}\right)$ of the $E \rightarrow Z$ isomerization (obtained by an Arrhenius plot) is higher in formylated compounds $\mathbf{1 1}$ compared to acetylated compounds $\mathbf{1 0}$ and is further increased by halogenation.

The unsubstituted $N$-formyl diazocine 11c and brominated $N A c$-diazocine 10a were also investigated in pure water since they are water-soluble $(11 \mathrm{c}: \approx 250 \mu \mathrm{M}, \mathbf{1 0 a}: \approx 150 \mu \mathrm{M})$. The highest $Z \rightarrow E$ conversion yields are observed by irradiation with $400 \mathrm{~nm}$ in water and the back-isomerization $E \rightarrow Z$ can be accomplished by irradiation with light in the range of 525 and $600 \mathrm{~nm}$ (Figure 3, Table 2).

The photoconversion yields $(Z \rightarrow E)$ of $N$-formyl diazocine 11c in water and bromo-NAc diazocine 10a are about $70 \%$, which do not differ significantly from unsubstituted NAc diazocine 10c $(72 \%)$ [15]. It is interesting to note that the half-lives and activation barriers $(E \rightarrow Z)$ are increasing $\left(t_{1 / 2} \approx 2-2.5\right.$-fold $)$ in water as compared to the less polar acetonitrile.

\section{Conclusion}

Five nitrogen-bridged diazocines (triazocines) were synthesized and characterized. Formyl $(\mathrm{R}=\mathrm{CHO})$ and acetyl groups ( $\mathrm{R}=\mathrm{Ac}$ ) were introduced at the $\mathrm{CH}_{2} \mathrm{NR}$ bridge and the distant phenyl rings are $\mathrm{Br}$ and I substituted. In contrast to previous approaches, the azo cyclization (ring closure) was achieved via the oxidation of the bis-anilines 7 with $m$ CPBA ( $\approx 60 \%$ yield). Among the nitrogen-bridged diazocines compounds 10a and 11c are water soluble and retained their high switching efficiency $(\approx 70 \%)$ also in water. The half-lives of the metastable $E$-isomers are larger for the $N$-formyl diazocines $11 a-c$ compared to the acetylated compounds $\mathbf{1 0 a - c}$ and generally, the half-lives are larger in water than in acetonitrile. Halogen atoms

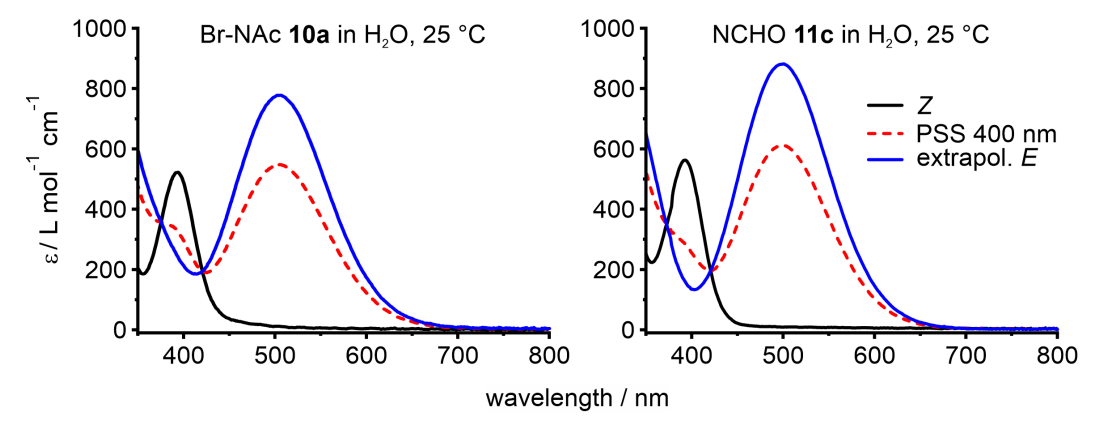

Figure 3: UV-vis spectra of 3-bromo-NAc-diazocine 10a and N-formyl-diazocine 11c in water. Spectra of $Z$-isomers (black curve), the photostationary states at $400 \mathrm{~nm}$ (dashed red line), and the extrapolated spectra of the pure $E$-isomers (blue).

Table 2: Photophysical properties of water-soluble $\mathrm{N}$-diazocines $10 \mathrm{a}, 10 \mathrm{c}$, and 11c in $\mathrm{H}_{2} \mathrm{O}$.

\begin{tabular}{|c|c|c|c|c|c|c|c|c|}
\hline & \multicolumn{8}{|c|}{$\mathrm{H}_{2} \mathrm{O}$} \\
\hline & $\lambda_{\max (\mathrm{Z})}$ & $\lambda_{\max (\mathrm{E})}$ & $\varepsilon_{\lambda \max (Z)}$ & $\varepsilon_{\lambda \max (\mathrm{E})}$ & $\Gamma_{Z \rightarrow E^{a}}$ & $t_{1 / 2}\left(25^{\circ} \mathrm{C}\right)$ & $E_{\mathrm{A}}$ & $\ln (A)$ \\
\hline & \multicolumn{2}{|c|}{$\mathrm{nm}$} & \multicolumn{2}{|c|}{$\mathrm{L} \mathrm{mol}{ }^{-1} \mathrm{~cm}^{-1}$} & $\%$ & $\min$ & $\mathrm{kJ} \mathrm{mol}^{-1}$ & \\
\hline Br-NAc 10a & 394 & 502 & 534 & 975 & 70 & 69.6 & 99.9 & 31.6 \\
\hline $\mathrm{NCHO} 11 \mathrm{c}$ & 393 & 500 & 567 & 871 & 69 & 198 & 97.8 & 29.7 \\
\hline NAc 10c & 393 & 502 & 564 & 850 & 72 & 72.8 & 90.4 & 27.7 \\
\hline
\end{tabular}

aExtrapolated values (for details, see Supporting Information File 1, section IV). 
$\mathrm{Br}$ and $\mathrm{I}$ at the phenyl rings in 3-position as in 10a,b, and 11a,b are a good starting point for further functionalization $[17,20,24]$. We conclude that $\mathrm{CH}_{2} \mathrm{NAc}$ and $\mathrm{CH}_{2} \mathrm{NCHO}$ bridged diazocines (triazocines) are promising candidates for applications in biological environments and particularly as photoswitches in light-activatable drugs.

\section{Supporting Information}

\section{Supporting Information File 1}

Analytical equipment, experimental procedures, NMR and $\mathrm{UV}$-vis spectra.

[https://www.beilstein-journals.org/bjoc/content/ supplementary/1860-5397-17-107-S1.pdf]

\section{Acknowledgments}

The authors thank Malte Wellmann for his assistance in synthesis.

\section{Funding}

The authors gratefully acknowledge financial support by the Deutsche Forschungsgesellschaft (DFG) within the Sonderforschungsbereich 677, "Function by Switching".

\section{ORCID ${ }^{\circledR}$ iDs}

Jeremy Rudtke - https://orcid.org/0000-0001-8079-7715

Rainer Herges - https://orcid.org/0000-0002-6396-6991

\section{Preprint}

A non-peer-reviewed version of this article has been previously published as a preprint: https://doi.org/10.3762/bxiv.2021.16.v1

\section{References}

1. Siewertsen, R.; Neumann, H.; Buchheim-Stehn, B.; Herges, R.; Näther, C.; Renth, F.; Temps, F. J. Am. Chem. Soc. 2009, 131, 15594-15595. doi:10.1021/ja906547d

2. Siewertsen, R.; Schönborn, J. B.; Hartke, B.; Renth, F.; Temps, F. Phys. Chem. Chem. Phys. 2011, 13, 1054-1063. doi:10.1039/c0cp01148g

3. Moormann, W.; Langbehn, D.; Herges, R. Synthesis 2017, 49, 3471-3475. doi:10.1055/s-0036-1590685

4. Moormann, W.; Langbehn, D.; Herges, R. Beilstein J. Org. Chem. 2019, 15, 727-732. doi:10.3762/bjoc.15.68

5. Samanta, S.; Qin, C.; Lough, A. J.; Woolley, G. A. Angew. Chem., Int. Ed. 2012, 51, 6452-6455. doi:10.1002/anie.201202383

6. Sell, H.; Näther, C.; Herges, R. Beilstein J. Org. Chem. 2013, 9, 1-7. doi:10.3762/bjoc.9.1

7. Li, S.; Eleya, N.; Staubitz, A. Org. Lett. 2020, 22, 1624-1627. doi:10.1021/acs.orglett.0c00122
8. Hammerich, M.; Schütt, C.; Stähler, C.; Lentes, P.; Röhricht, F.; Höppner, R.; Herges, R. J. Am. Chem. Soc. 2016, 138, 13111-13114. doi:10.1021/jacs.6b05846

9. Heintze, L.; Schmidt, D.; Rodat, T.; Witt, L.; Ewert, J.; Kriegs, M.; Herges, R.; Peifer, C. Int. J. Mol. Sci. 2020, 21, 8961-8981. doi:10.3390/ijms21238961

10. Beharry, A. A.; Woolley, G. A. Chem. Soc. Rev. 2011, 40, 4422-4437. doi:10.1039/c1cs15023e

11. Szymański, W.; Beierle, J. M.; Kistemaker, H. A. V.; Velema, W. A.; Feringa, B. L. Chem. Rev. 2013, 113, 6114-6178. doi:10.1021/cr300179f

12. Hüll, K.; Morstein, J.; Trauner, D. Chem. Rev. 2018, 118, 10710-10747. doi:10.1021/acs.chemrev.8b00037

13. Fuchter, M. J. J. Med. Chem. 2020, 63, 11436-11447. doi:10.1021/acs.jmedchem.0c00629

14. Lubbe, A. S.; Szymanski, W.; Feringa, B. L. Chem. Soc. Rev. 2017, 46, 1052-1079. doi:10.1039/c6cs00461j

15. Lentes, P.; Stadler, E.; Röhricht, F.; Brahms, A.; Gröbner, J.; Sönnichsen, F. D.; Gescheidt, G.; Herges, R. J. Am. Chem. Soc. 2019, 141, 13592-13600. doi:10.1021/jacs.9b06104

16. Lentes, P.; Frühwirt, P.; Freißmuth, H.; Moormann, W.; Kruse, F.; Gescheidt, G.; Herges, R. J. Org. Chem. 2021, 86, 4355-4360. doi:10.1021/acs.joc.1c00065

17. Cabré, G.; Garrido-Charles, A.; González-Lafont, À.; Moormann, W.; Langbehn, D.; Egea, D.; Lluch, J. M.; Herges, R.; Alibés, R.; Busqué, F.; Gorostiza, P.; Hernando, J. Org. Lett. 2019, 21, 3780-3784. doi:10.1021/acs.orglett.9b01222

18. Trads, J. B.; Hüll, K.; Matsuura, B. S.; Laprell, L.; Fehrentz, T.; Görldt, N.; Kozek, K. A.; Weaver, C. D.; Klöcker, N.; Barber, D. M.; Trauner, D. Angew. Chem., Int. Ed. 2019, 58, 15421-15428. doi:10.1002/anie.201905790

19. Preußke, N.; Moormann, W.; Bamberg, K.; Lipfert, M.; Herges, R.; Sönnichsen, F. D. Org. Biomol. Chem. 2020, 18, 2650-2660. doi:10.1039/c9ob02442e

20. Thapaliya, E. R.; Zhao, J.; Ellis-Davies, G. C. R. ACS Chem. Neurosci. 2019, 10, 2481-2488. doi:10.1021/acschemneuro.8b00734

21. Schehr, M.; Hugenbusch, D.; Moje, T.; Näther, C.; Herges, R. Beilstein J. Org. Chem. 2018, 14, 2799-2804. doi:10.3762/bjoc.14.257

22. Maier, M. S.; Hüll, K.; Reynders, M.; Matsuura, B. S.; Leippe, P.; Ko, T.; Schäffer, L.; Trauner, D. J. Am. Chem. Soc. 2019, 141, 17295-17304. doi:10.1021/jacs.9b08794

23. Liebig, J. Ann. Pharm. (Lemgo, Ger.) 1832, 1, 182-230. doi:10.1002/jlac.18320010203

24. Biffis, A.; Centomo, P.; Del Zotto, A.; Zecca, M. Chem. Rev. 2018, 118, 2249-2295. doi:10.1021/acs.chemrev.7b00443 


\section{License and Terms}

This is an Open Access article under the terms of the Creative Commons Attribution License (https://creativecommons.org/licenses/by/4.0). Please note that the reuse, redistribution and reproduction in particular requires that the author(s) and source are credited and that individual graphics may be subject to special legal provisions.

The license is subject to the Beilstein Journal of Organic Chemistry terms and conditions:

(https://www.beilstein-journals.org/bjoc/terms)

The definitive version of this article is the electronic one which can be found at:

$\underline{\text { https://doi.org/10.3762/bjoc.17.107 }}$ 